\title{
Prevalence and clinical consequences of Hepatitis $E$ in patients who underwent liver transplantation for chronic Hepatitis $C$ in the United States
}

Ludi Koning 1,3, Michael R. Charlton ${ }^{4}$, Suzan D. Pas², Julie K. Heimbach ${ }^{3}$, Albert DME Osterhaus², Kymberly D. Watt ${ }^{3}$, Harry LA Janssen ${ }^{5}$, Robert J. de Knegt ${ }^{1}$ and Annemiek A. van der Eijk ${ }^{2^{*}}$

\begin{abstract}
Background: Infection with hepatitis E virus (HEV) in immunocompromised patients can lead to severe liver disease. Treatment options for HEV include peginterferon or ribavirin, routinely also used for the treatment of hepatitis $\mathrm{C}$ virus (HCV) infection.

We determined the prevalence and clinical consequences of HEV in United States (US) based patients who underwent liver transplantation (LT) for chronic HCV.
\end{abstract}

Methods: Seroprevalence of HEV in 145 US LT recipients with a history of chronic HCV was determined pre-LT, 1, 3 and 5 years post-LT. All last available samples and all samples in IgM positive patients and post-LT IgG seroconverters were tested for HEV RNA.

Results: Overall anti-HEV seroprevalence was $42 \%$. Five patients were HEV IgM positive pre-LT, one patient had IgM seroconversion post-LT and eight patients had lgG seroconversion post-LT. None of the tested samples were positive for HEV RNA. Eight out of nine of the post-LT seroconverters had been treated for HCV recurrence before or at the moment of seroconversion.

Conclusions: $L T$ recipients in the US are at risk of acquiring HEV. Post-LT HCV treatment with interferons and/or ribavirin may have protected patients against chronic HEV. With the arrival of new direct antiviral agents for the treatment of HCV and the elimination of peginterferon and ribavirin from HCV treatment regimens, the prevalence of chronic HEV in this population may rise again.

\section{Background}

Hepatitis E virus (HEV), an enterically transmitted virus that is known for causing acute hepatitis, was first isolated in 1990 [1]. HEV is a non-enveloped virus with a single-stranded, positive sense RNA genome of approximately 7,500 base pairs and three partially overlapping open reading frames (ORF 1-3) [2]. Up to date, there are four genotypes prevalent known to infect humans. Genotype 1 and 2 are endemic in developing countries and mainly transmitted through contaminated

\footnotetext{
* Correspondence: a.vandereijk@erasmusmc.nl

2Department of Viroscience, Erasmus University Medical Center, room NA-1019, Wytemaweg 80, 3015 CN Rotterdam, The Netherlands Full list of author information is available at the end of the article
}

water, while genotypes 3 and 4 are sporadically seen in industrialized countries and thought to be zoonotic of origin $[3,4]$.

While in most cases HEV infection is usually a selflimiting disease, in the past years multiple reports have emerged on immunocompromised patients, especially solid organ transplant (SOT) recipients, developing chronic HEV infection [5-7]. Reports on HEV infections in SOT recipients in the United States are scarce. Almost all well-defined cohort studies in industrialized countries on HEV infection in SOT recipients up to now have been done in Europe and these results cannot be automatically extrapolated to the situation in the US due to geographical and demographic 
differences. One study in HIV-infected liver and kidney transplant candidates in the US showed a pre-transplant seroprevalence of almost $20 \%$ [8]. Estimates of the seroprevalence of HEV in the general population (including blood donors) in the US are reaching up to $22 \%$ [9-13]. Swine-human contact is seen as an important possible source for HEV transmission in the US: HEV infection occurs in more than $80 \%$ of some pig herds in the US [14] and HEV RNA has been found in pig feces on multiple US farms and pig livers sold in local US grocery stores [15-17]. Veterinarians working with swine are 1.5 times more likely to be HEV IgG positive than blood donors from the same area [10]. In US blood donors, an HEV seroprevalence of up to $22 \%$ has been reported, making blood transfusions a likely mode of transmission as well [9-11].

Consequently, SOT recipients in the US are at risk of acquiring HEV infection. Early detection of HEV infection in these patients is crucial, since chronic HEV in SOT recipients can lead to rapid fibrosis and even cirrhosis [18-20].

Chronic HEV can be adequately managed by dose reduction of immunosuppressive medication or treatment with peginterferon alpha or ribavirin (RBV), compounds also used for the treatment of hepatitis $\mathrm{C}$ virus (HCV) infection [21-24]. Currently, no studies on HEV infection in HCV infected SOT recipients are available. On one hand, there is a risk of development of progressive or even fulminant liver disease when co-infection with HEV in these patients occurs. On the other hand, chronic HEV infection may be less prevalent due to treatment of $\mathrm{HCV}$.

To gain more insight into the prevalence of hepatitis $E$ infection in SOT recipients in the US and the influence of HCV treatment on the incidence and clinical course of HEV we conducted the current study in a cohort of patients with a history of $\mathrm{HCV}$ that underwent a liver transplantation in the Mayo Clinic in Rochester, Minnesota.

\section{Methods}

\section{Patients and samples}

From 1997 through 2010 serum samples were prospectively collected according to a standard protocol in patients with a history of chronic hepatitis $C$ infection that underwent liver transplantation for end stage liver disease or hepatocellular carcinoma in the Mayo Clinic in Rochester, Minnesota (US). No donor organs were obtained from executed prisoners or other institutionalized persons. Samples were collected in 145 patients at four time points: pre-transplantation (baseline), 1, 3 and 5 years post-liver transplantation and subsequently stored at $-70{ }^{\circ} \mathrm{C}$. Each enrolled subject had consented in future testing of archived bio-samples. Samples were shipped to the Erasmus University Medical Center in Rotterdam (The Netherlands) for hepatitis E testing. The study protocol conforms to the ethical guidelines of the 1975 Declaration of Helsinki and was approved by the Institutional Review Board of the Mayo Clinic in Rochester, Minnesota (US).

\section{HEV specific antibody detection}

First, all collected samples were tested for both HEV specific IgM and HEV specific IgG with the commercially available enzyme-linked immunosorbent assay (ELISA) (Wantai, Beijing, China), used according to the manufacturer's instructions.

\section{HEV-RNA detection}

Second, all samples in patients with HEV specific IgM antibodies and patients with HEV specific IgG seroconversion post-LT were tested for the presence of HEV RNA by an internally controlled quantitative real-time RT-PCR, described previously [6]. The RT-PCR has a lower limit of detection (95\% hit rate) of $143 \mathrm{IU} / \mathrm{ml}$ as determined by the 1st WHO standard for HEV RNA NAT-Based assays (6329/10, Paul Ehrlich Institute, Germany). Finally, all last available samples in the 145 patients were tested for HEV RNA to detect any ongoing active HEV infection at the last follow up point, since seroconversion in immunocompromised patients is often delayed and these patients might not have seroconverted yet.

\section{Results}

A total of 370 samples in 145 LT-recipients were available for analysis. Distribution of samples over time and serology test results are given in Fig. 1. Baseline characteristics are given in Table 1.

\section{IgG seroconversion}

A total of 61 patients (42\%) had HEV specific IgG antibodies at some point from baseline up to last follow up. Seroprevalence of HEV at baseline was higher in men compared to women, however, overall seroprevalence from baseline up to last follow up did not differ between sexes: $N=60(40 \%)$ for men and $N=18$ (33\%) for women $(p=0.418)$. Of the 53 patients that had HEV specific IgG antibodies at baseline, 46 had at least one follow-up sample post-LT. Fifteen of these patients (33 \%) with IgG antibodies at baseline had IgG loss at some point post-LT. A total of 125 patients had a baseline sample and at least one follow up sample available. Eight patients (6.4\%) were IgG negative at baseline and showed IgG seroconversion post-LT; four at year 1, one at year 3 and three at year 5 post-LT. Two of these eight patients had IgG loss after post-LT seroconversion. 


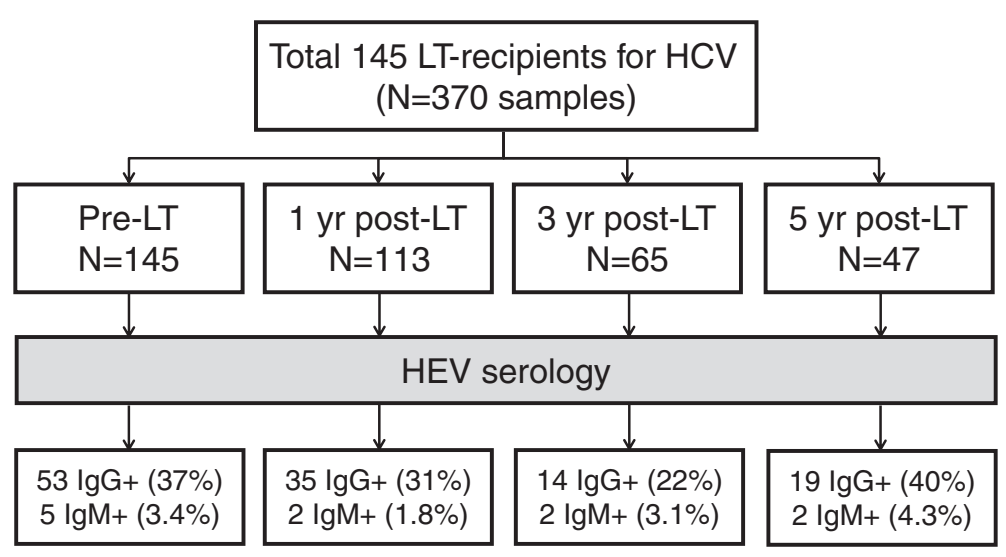

Fig. 1 Sample distribution and Hepatitis E serology in 145 Liver Transplant Recipients. Abbreviations: LT, Liver Transplant; HEV, Hepatitis E Virus

\section{IgM seroconversion}

Only six out of 145 patients (4.1\%) had IgM antibodies against HEV. Five patients had IgG and IgM antibodies against HEV at baseline and one patient, who had been IgG positive from baseline up to 5 years post-LT, seroconverted IgM at year 5 post-LT (see also Table 2). One of the 6 IgM-positive patients had IgG and IgM loss post-LT, another patient experienced IgG loss but remained IgM positive.

\section{Post-LT HEV infection}

None of the last available samples in the 145 patients or any of the samples in the IgM positive and IgG seroconverters were positive for HEV RNA. We hypothesized that $\mathrm{HCV}$ infected LT-recipients were protected against chronic HEV infection due to concurrent treatment with either (peg) interferon or RBV for the treatment of HCV. To test this hypothesis we selected the patients that were most likely to have had active infection post-LT, namely: the patients that had IgM and/or IgG seroconversion post-LT. All 8 IgG seroconverters and the single IgM positive patient that seroconverted after LT met this definition and were further explored (see Table 2).

Table 1 Baseline characteristics in LT recipients with a history of HCV infection

\begin{tabular}{llll}
\hline & $\begin{array}{l}\text { HEV IgG positive } \\
N=53\end{array}$ & $\begin{array}{l}\text { HEV IgG negative } \\
N=92\end{array}$ & $p$-value \\
\hline Mean age, years & $53 \pm 7$ & $51 \pm 8$ & 0.153 \\
Male sex & $45(85 \%)$ & $64(70 \%)$ & 0.047 \\
Caucasian ethnicity & $47(88 \%)$ & $79(84 \%)$ & 0.615 \\
Residing in Minnesota & $29(53 \%)$ & $35(37 \%)$ & 0.077 \\
History of alcohol abuse & $26(49 \%)$ & $34(37 \%)$ & 0.166 \\
HCV genotype 1 & $28(67 \%)$ & $63(83 \%)$ & 0.066 \\
\hline
\end{tabular}

LT liver transplant, $H C V$ Hepatitis C virus, HEV Hepatitis E virus
All but one patient was treated with (peg) interferon and/or RBV before or at the time of seroconversion.

\section{Discussion}

In this study we examined the prevalence and impact of serological evidence of HEV infection among a welldefined cohort of US liver transplant recipients with a history of HCV infection. The impact of HEV infection among solid organ transplant recipients is likely to be greatest among patients with pre-existing liver injury such as caused by chronic HCV, since acute on chronic infection will most likely lead to an aggravated clinical course. Post-transplant HCV infection is the most common cause of graft loss among liver transplant recipients, raising the possibility that the consequences of posttransplant HEV infection might be most readily apparent in this group of patients. Our analysis of HEV infection in a relatively large cohort of liver transplant recipients with $\mathrm{HCV}$ infection has produced several potentially important results that merit detailed consideration. The first important observation is that in this cohort, more than four out of ten liver transplant recipients with a history of HCV infection have been in contact with HEV. This finding highlights that these patients are at considerable risk of exposure to $\mathrm{HEV}$, which may lead to chronic infection or accelerated liver disease. Indeed, we showed that transplant recipients in the US are at risk of acquiring HEV infection following liver transplantation, considering that nine out of 125 patients $(7.2 \%)$ with at least one follow up sample had HEV seroconversion post-LT.

There are several explanations why over four out of ten patients in this cohort of US liver transplant recipients with a history of $\mathrm{HCV}$ infection have HEV antibodies. Since HCV is a blood borne disease, HEV infection may share the same transmission route as $\mathrm{HCV}$. An association between intravenous drug use in $\mathrm{HCV}$ infected patients 
Table 2 Characteristics of nine post-LT HEV seroconverting patients with a history of HCV infection

\begin{tabular}{|c|c|c|c|c|c|c|c|c|c|}
\hline & Age at LT & Gender & Ethnicity & LT year & $\begin{array}{l}\text { Type of serologic } \\
\text { conversion }\end{array}$ & $\begin{array}{l}\text { Conversion } \\
\text { year (from LT) }\end{array}$ & $\begin{array}{l}\text { Post-LT HCV } \\
\text { treatment }\end{array}$ & $\begin{array}{l}\text { Treatment year } \\
\text { post-LT }\end{array}$ & $\begin{array}{l}\text { Treatment } \\
\text { medication }\end{array}$ \\
\hline Pt 1 & 46 & Male & Caucasian & 1998 & $\lg M$ & 5 & Yes & $1-5$ & $\mathrm{IFN}+\mathrm{RBV}$ \\
\hline Pt 2 & 48 & Male & Caucasian & 1998 & $\lg G$ & 1 & Yes & $0-1$ & IFN + RBV \\
\hline Pt 3 & 39 & Male & Native Hawaiian & 2000 & $\lg G$ & 5 & Yes & $2-3$ & $\mathrm{IFN}+\mathrm{RBV}$ \\
\hline Pt 4 & 36 & Female & Caucasian & 2001 & $\lg G$ & 1 & Yes & $0-1$ & $\mathrm{IFN}+\mathrm{RBV}$ \\
\hline Pt 5 & 47 & Male & Other NS & 2001 & $\lg G$ & 1 & Yes & 0 & IFN \\
\hline Pt 6 & 51 & Male & Caucasian & 2001 & $\lg G$ & 5 & Yes & $2-4$ & IFN + RBV \\
\hline Pt 7 & 47 & Male & Caucasian & 2003 & $\lg G$ & 3 & Yes & $1-4$ & $\mathrm{IFN}+\mathrm{RBV}$ \\
\hline Pt 8 & 51 & Male & Caucasian & 2004 & $\lg G$ & 5 & Yes & $0-3$ & IFN + RBV \\
\hline Pt 9 & 54 & Male & Caucasian & 2009 & $\lg G$ & 1 & No & $\mathrm{N} / \mathrm{A}$ & N/A \\
\hline
\end{tabular}

LT Liver transplant, HEV Hepatitis E virus, HCV Hepatitis C virus, IFN (peg) interferon, RBV ribavirin, Other NS Other than Caucasian, Hispanic, Black or Asian, not specified, N/A not applicable

and the prevalence of HEV IgG antibodies has been inconsistently reported $[25,26]$. Another possible transmission route is through transfusion with blood products. There is a considerable seroprevalence of HEV in blood donors in the US with anti-HEV antibodies of up to $22 \%$, though no active infection in US cohorts has been found [9-11]. In contrast, in European cohorts, HEV RNA was found in plasma and blood donors [27-33] leading to HEV infection in patients receiving those blood components [33]. As long as blood products are not routinely screened for HEV RNA, US physicians should be aware of this possible transmission route. LT recipients usually have received multiple blood products over the course of their disease. $\mathrm{HCV}$ treated LT recipients are even more likely of receiving blood transfusion due to treatment-induced anemia, further increasing the chance of receiving blood products from an HEV viremic donor. Patients are also at risk of acquiring HEV through infection of the donor organ as a recent report on a liver transplant recipient showed [34]. Finally, the average age in this cohort was 51.8 years and several studies have shown that HEV seroprevalence increases with age $[10,11,35,36]$.

One of the unexpected observations in our analysis was that, despite a substantial number of patients seroconverting to anti-HEV IgM and/or anti-HEV IgG following liver transplantation, we did not find any active HEV infection in this cohort. It is possible that HEV viremia was missed in our study due to the time between serum draws that were available for analysis. HEV seroconversion may have occurred with (spontaneous) clearance of active HEV infection and subsequent loss of HEV antibodies over time due to immunosuppressive therapy, as illustrated by HEV IgG loss post-LT in one third of patients with HEV IgG antibodies at baseline. We may also have missed patients that did not seroconvert at all despite infection due to their immunosuppressive state, since HEV seroconversion is often delayed or even absent in these patients $[6,24,37,38]$. Patients that obtained HEV infection after the last follow up sample and subsequently died will have been missed as well. Our results may, therefore, have underestimated the severity of acute HEV infection.

We used the most sensitive HEV serologic test available at the moment [39-41] and an internally controlled quantitative real-time RT-PCR, which has been an effective and reproducible tool for detecting HEV RNA in other cohorts [35, 42]. The effects of immunosuppression, which include suppression of antibody production and an increase of levels of viremia (e.g. for HCV, HBV, CMV), may have resulted in an underestimation of the seroprevalence of anti-HEV in this cohort but should not have affected the numbers regarding prevalence of active HEV infection. Our results should generally be viewed as reassuring in that no active HEV infection was found in any of the patients at last follow up. Moreover, HEV infection in SOT recipients does not always progress to chronicity [37]. A further consideration in the lack of active HEV infection in our analysis is that eight out of nine post-LT anti-HEV seroconverters were treated with either RBV or (peg) interferon. Both of these agents are known to be effective therapies for HEV infection and may have contributed to HEV clearance. As HCV treatment initiation is often based on clinical parameters indicating (recurrent) hepatitis, it is possible that superinfection with HEV may have contributed to the likelihood of initiation of anti-HCV therapy. Soon, new antiviral agents, including interferonand ribavirin-free protocols, against $\mathrm{HCV}$ will become available for the treatment of HCV infection. The disappearance of interferon and RBV from HCV treatment regimens may increase the risk of acquiring chronic HEV and subsequent development of fibrosis and cirrhosis, as these new agents will most likely not have activity against HEV. HCV liver transplant recipients not treated for HEV are currently still at risk of developing chronic HEV. 
Limitations of this study include a lack of a comparative non-HCV infected group of liver transplant recipients, the retrospective nature of the study and patients that were lost to follow up due to their transferring care to a local hospital.

\section{Conclusions}

LT recipients in the US are at risk of acquiring HEV. Therefore, screening of HEV in LT recipients should be carried out routinely, especially when there are clinical signs of (progressive) hepatitis. Evaluation of immunocompromised patients should include HEV RNA testing, since antibody detection is often delayed in these patients. Due to the lack of FDA-approved HEV RNA tests and high interlaboratory variability in PCR performance [43], we recommend to have samples tested in a laboratory with extensive experience and up to date assays. $\mathrm{HCV}$ infected LT recipients may be protected against the development of chronic HEV through treatment against HCV. However, HEV infection should be best managed through dose reduction of immunosuppressive medication and/or treatment with low-dose RBV [44], avoiding overtreatment of $\mathrm{HCV}$ infected patients. Due to the arrival of new interferon- and RBV-free $\mathrm{HCV}$ regimens not active against HEV, HCV infected LT recipients will again be at risk of acquiring (chronic) HEV in the nearby future.

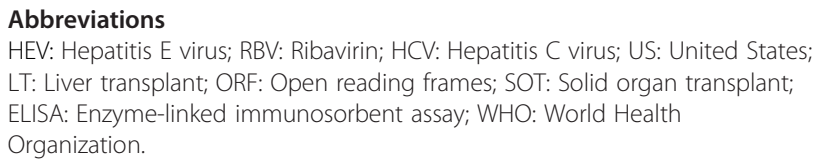

\section{Competing interest}

The authors declare that they have no competing interests.

\section{Authors' contributions}

LK, MRC, JKH, KDW, RJK and AAE designed the study. SDP performed sample analysis. LK analysed data and wrote the manuscript. HLAJ and ADMEO gave conceptual advice. MRC and AAE supervised the project. All authors discussed the results and implications and commented on the manuscript at all stages. All authors read and approved the final manuscript.

\section{Acknowledgments}

We thank Kristin Kornwell, RN and Brenda Ingalls Hanson for research authorization, Diane Soeffker for sample collection and Mark Pronk for technical assistance.

\section{Funding \\ This study was supported by the Virgo consortium, funded by the Dutch government (FES0908), by the Netherlands Genomics Initiative (NGI) project number 050-060-452 and by the European Community Seventh Framework Programme (FP7/2007-2013) under project EMPERIE (grant agreement no. 223498).}

\section{Author details}

'Department of Gastroenterology and Hepatology, Erasmus University Medical Center, Rotterdam, The Netherlands. '2Department of Viroscience, Erasmus University Medical Center, room NA-1019, Wytemaweg 80, 3015 CN Rotterdam, The Netherlands. ${ }^{3}$ Mayo Clinic Transplant Center, Rochester, MN, USA. Intermountain Medical Center, Transplant Center, Salt Lake City, UT,
USA. ${ }^{5}$ Toronto Centre for Liver Disease, Toronto Western \& General Hospital, University Health Network, Toronto, Canada.

Received: 27 January 2015 Accepted: 12 August 2015

Published online: 02 September 2015

\section{References}

1. Reyes GR, Purdy MA, Kim JP, Luk KC, Young LM, Fry KE, et al. Isolation of a CDNA from the virus responsible for enterically transmitted non-A, non-B hepatitis. Science. 1990;247(4948):1335-9.

2. Tam AW, Smith MM, Guerra ME, Huang CC, Bradley DW, Fry KE, et al. Hepatitis E virus (HEV): molecular cloning and sequencing of the full-length viral genome. Virology. 1991;185(1):120-31.

3. Okamoto H. Genetic variability and evolution of hepatitis E virus. Virus Res. 2007;127(2):216-28.

4. Lewis HC, Wichmann O, Duizer E. Transmission routes and risk factors for autochthonous hepatitis $\mathrm{E}$ virus infection in Europe: a systematic review. Epidemiol Infect. 2010;138(2):145-66.

5. Kamar N, Selves J, Mansuy JM, Ouezzani L, Peron JM, Guitard J, et al. Hepatitis E virus and chronic hepatitis in organ-transplant recipients. N Engl J Med. 2008;358(8):811-7.

6. Pas SD, de Man RA, Mulders C, Balk AH, van Hal PT, Weimar W, et al. Hepatitis $E$ virus infection among solid organ transplant recipients, the Netherlands. Emerg Infect Dis. 2012;18(5):869-72.

7. Pischke S, Stiefel P, Franz B, Bremer B, Suneetha PV, Heim A, et al. Chronic hepatitis e in heart transplant recipients. Am J Transplant. 2012;12(11):3128-33.

8. Sherman KE, Terrault N, Barin B, Rouster SD, Shata MT, Investigators H-T. Hepatitis E infection in HIV-infected liver and kidney transplant candidates. J Viral Hepat. 2014;21(8):e74-7.

9. Thomas DL, Yarbough PO, Vlahov D, Tsarev SA, Nelson KE, Saah AJ, et al. Seroreactivity to hepatitis $E$ virus in areas where the disease is not endemic. J Clin Microbiol. 1997;35(5):1244-7.

10. Meng XJ, Wiseman B, Elvinger F, Guenette DK, Toth TE, Engle RE, et al. Prevalence of antibodies to hepatitis $E$ virus in veterinarians working with swine and in normal blood donors in the United States and other countries. J Clin Microbiol. 2002;40(1):117-22.

11. Xu C, Wang RY, Schechterly CA, Ge S, Shih JW, Xia NS, et al. An assessment of hepatitis E virus (HEV) in US blood donors and recipients: no detectable HEV RNA in 1939 donors tested and no evidence for HEV transmission to 362 prospectively followed recipients. Transfusion. 2013:53(10 Pt 2):2505-11.

12. Kuniholm MH, Purcell RH, McQuillan GM, Engle RE, Wasley A, Nelson KE. Epidemiology of hepatitis $\mathrm{E}$ virus in the United States: results from the Third National Health and Nutrition Examination Survey, 1988-1994. J Infect Dis. 2009;200(1):48-56.

13. Ditah I, Ditah F, Devaki P, Ditah C, Kamath PS, Charlton M. Current epidemiology of hepatitis E virus infection in the United States: low seroprevalence in the National Health and Nutrition Evaluation Survey. Hepatology. 2014;60(3):815-22.

14. Meng XJ, Purcell RH, Halbur PG, Lehman JR, Webb DM, Tsareva TS, et al. A novel virus in swine is closely related to the human hepatitis $\mathrm{E}$ virus. Proc Natl Acad Sci U S A. 1997:94(18):9860-5.

15. Kasorndorkbua C, Opriessnig T, Huang FF, Guenette DK, Thomas PJ, Meng $X J$, et al. Infectious swine hepatitis $E$ virus is present in pig manure storage facilities on United States farms, but evidence of water contamination is lacking. Appl Environ Microbiol. 2005;71(12):7831-7.

16. Kase JA, Correa MT, Sobsey MD. Detection and molecular characterization of swine hepatitis E virus in North Carolina swine herds and their faecal wastes. J Water Health. 2009;7(2):344-57.

17. Feagins AR, Opriessnig T, Guenette DK, Halbur PG, Meng XJ. Detection and characterization of infectious Hepatitis E virus from commercial pig livers sold in local grocery stores in the USA. J Gen Virol. 2007;88(Pt 3):912-7.

18. Haagsma EB, van den Berg AP, Porte RJ, Benne CA, Vennema H, Reimerink $\mathrm{JH}$, et al. Chronic hepatitis E virus infection in liver transplant recipients. Liver Transpl. 2008:14(4):547-53.

19. Gerolami R, Moal V, Colson P. Chronic hepatitis E with cirrhosis in a kidneytransplant recipient. N Engl J Med. 2008;358(8):859-60.

20. Kamar N, Mansuy JM, Cointault O, Selves J, Abravanel F, Danjoux M, et al. Hepatitis E virus-related cirrhosis in kidney- and kidney-pancreas-transplant recipients. Am J Transplant. 2008;8(8):1744-8. 
21. Kamar N, Rostaing L, Abravanel F, Garrouste C, Esposito L, CardeauDesangles I, et al. Pegylated interferon-alpha for treating chronic hepatitis $E$ virus infection after liver transplantation. Clin Infect Dis. 2010;50(5):e30-3.

22. Haagsma EB, Riezebos-Brilman A, van den Berg AP, Porte RJ, Niesters HG Treatment of chronic hepatitis $E$ in liver transplant recipients with pegylated interferon alpha-2b. Liver Transpl. 2010;16(4):474-7.

23. Kamar N, Rostaing L, Abravanel F, Garrouste C, Lhomme S, Esposito L, et al. Ribavirin therapy inhibits viral replication on patients with chronic hepatitis e virus infection. Gastroenterology. 2010;139(5):1612-8.

24. Koning L, Pas SD, de Man RA, Balk AH, de Knegt RJ, ten Kate FJ, et al. Clinical implications of chronic hepatitis E virus infection in heart transplant recipients. J Heart Lung Transplant. 2013;32(1):78-85.

25. Kaba M, Brouqui P, Richet H, Badiaga S, Gallian P, Raoult D, et al. Hepatitis E virus infection in sheltered homeless persons. Fr Emerg Infect Dis. 2010;16(11):1761-3.

26. Larrat S, Gaillard S, Baccard M, Piroth L, Cacoub P, Pol S, et al. Hepatitis e virus infection in sheltered homeless persons, france. Emerg Infect Dis. 2012;18(6):1031. author reply 2.

27. Baylis SA, Gartner T, Nick S, Ovemyr J, Blumel J. Occurrence of hepatitis E virus RNA in plasma donations from Sweden, Germany and the United States. Vox Sang. 2012;103(1):89-90.

28. ljaz S, Szypulska R, Tettmar Kl, Kitchen A, Tedder RS. Detection of hepatitis E virus RNA in plasma mini-pools from blood donors in England. Vox Sang. 2012;102(3):272

29. Corman VM, Drexler JF, Eckerle I, Roth WK, Drosten C, Eis-Hubinger AM. Zoonotic hepatitis E virus strains in German blood donors. Vox Sang. 2013;104(2):179-80

30. Juhl D, Baylis SA, Blumel J, Gorg S, Hennig H. Seroprevalence and incidence of hepatitis $\mathrm{E}$ virus infection in German blood donors. Transfusion. 2014;54(1):49-56

31. Cleland A, Smith L, Crossan C, Blatchford O, Dalton HR, Scobie L, et al. Hepatitis E virus in Scottish blood donors. Vox Sang. 2013;105(4):283-9.

32. Slot E, Hogema B, Riezebos-Brilman A, Kok T, Molier M, Zaaijer H. Silent hepatitis E virus infection in Dutch blood donors, 2011 to 2012. Euro Surveill. 2013;18(31)1-7.

33. Hewitt PE, ljaz S, Brailsford SR, Brett R, Dicks S, Haywood B, et al. Hepatitis E virus in blood components: a prevalence and transmission study in southeast England. Lancet. 2014;384(9956):1766-73.

34. Schlosser B, Stein A, Neuhaus R, Pahl S, Ramez B, Kruger DH, et al. Liver transplant from a donor with occult HEV infection induced chronic hepatitis and cirrhosis in the recipient. J Hepatol. 2012;56(2):500-2.

35. Park HK, Jeong SH, Kim JW, Woo BH, Lee DH, Kim HY, et al. Seroprevalence of anti-hepatitis E virus (HEV) in a Korean population: comparison of two commercial anti-HEV assays. BMC Infect Dis. 2012;12:142.

36. Faber MS, Wenzel JJ, Jilg W, Thamm M, Hohle M, Stark K. Hepatitis E virus seroprevalence among adults. Germany Emerg Infect Dis. 2012;18(10):1654-7.

37. Kamar N, Garrouste C, Haagsma EB, Garrigue V, Pischke S, Chauvet C, et al. Factors associated with chronic hepatitis in patients with hepatitis E virus infection who have received solid organ transplants. Gastroenterology. 2011;140(5):1481-9.

38. Versluis J, Pas SD, Agteresch HJ, de Man RA, Maaskant J, Schipper ME, et al. Hepatitis E virus: an underestimated opportunistic pathogen in recipients of allogeneic hematopoietic stem cell transplantation. Blood. 2013;122(6):1079-86.

39. Pas SD, Streefkerk RH, Pronk M, de Man RA, Beersma MF, Osterhaus AD, et al. Diagnostic performance of selected commercial HEV IgM and IgG ELISAs for immunocompromised and immunocompetent patients. J Clin Virol. 2013;58(4):629-34.

40. Abravanel F, Chapuy-Regaud S, Lhomme S, Miedouge M, Peron JM, Alric L, et al. Performance of anti-HEV assays for diagnosing acute hepatitis $E$ in immunocompromised patients. J Clin Virol. 2013;58(4):624-8.

41. Wenzel JJ, Preiss J, Schemmerer M, Huber B, Jilg W. Test performance characteristics of Anti-HEV lgG assays strongly influence hepatitis $E$ seroprevalence estimates. J Infect Dis. 2013;207(3):497-500.

42. Bendall $R$, Ellis $V$, ljaz $S$, Ali $R$, Dalton $H$. A comparison of two commercially available anti-HEV lgG kits and a re-evaluation of anti-HEV IgG seroprevalence data in developed countries. J Med Virol. 2010;82(5):799-805.

43. Baylis SA, Hanschmann KM, Blumel J, Nubling CM, Group HEVCS. Standardization of hepatitis E virus (HEV) nucleic acid amplification technique-based assays: an initial study to evaluate a panel of HEV strains and investigate laboratory performance. J Clin Microbiol. 2011;49(4):1234-9.

44. Kamar N, Bendall R, Legrand-Abravanel F, Xia NS, ljaz S, Izopet J, et al. Hepatitis E. Lancet. 2012;379(9835):2477-88.

\section{Submit your next manuscript to BioMed Central and take full advantage of:}

- Convenient online submission

- Thorough peer review

- No space constraints or color figure charges

- Immediate publication on acceptance

- Inclusion in PubMed, CAS, Scopus and Google Scholar

- Research which is freely available for redistribution

Submit your manuscript at www.biomedcentral.com/submit 